\title{
Association between ADORA2A and DRD2 Polymorphisms and Caffeine-Induced Anxiety
}

\author{
Emma Childs",', Christa Hohoff ${ }^{2}$, Jürgen Deckert ${ }^{2,3}, K^{2} \mathbf{X u}^{4}$, Judith Badner' and Harriet de Wit' \\ 'Department of Psychiatry, The University of Chicago, Chicago, IL, USA; ${ }^{2}$ Department of Psychiatry, University of Münster, Albert-Schweitzer-Str. \\ I I, Münster, Germany; ${ }^{3}$ Department of Psychiatry, University of Würzburg, Füchsleinstr. 15, Würzburg, Germany; ${ }^{4}$ Section of Human \\ Neurogenetics, Laboratory of Neurogenetics, National Institute on Alcohol Abuse and Alcoholism, National Institutes of Health, Bethesda, MD, \\ USA
}

\begin{abstract}
Caffeine produces mild psychostimulant and sometimes anxiogenic effects by antagonizing adenosine at $A_{1}$ and $A_{2 A}$ receptors, and perhaps through interactions with other transmitter systems. Adenosine receptors are colocalized and functionally interact with dopamine receptors in the brain. Thus, functional polymorphisms in the genes for either adenosine or dopamine receptors may affect responses to caffeine. In this study, we examined associations between self-reported anxiogenic effects of caffeine and variation in the genes for $A_{2 A}(A D O R A 2 A)$ and $D R D_{2}$ (DRD2) receptors. Healthy male and female individuals $(n=102)$, who consumed less than 300 mg caffeine per week, ingested capsules containing $0,50,150$, and $450 \mathrm{mg}$ caffeine under double-blind conditions in four separate experimental sessions. Subjective anxiety was measured before and at repeated times after capsules were consumed. At the I50 mg dose of caffeine, we found a significant association between caffeine-induced anxiety (Visual Analog Scales, VAS) and ADORA2A rs575 I 876 ( I 976C/T), rs2298383 (intron Ia) and rs4822492 (3'-flank), and DRD2 rs I I 10976 (intron 6). Caffeine-induced anxiety (VAS) was also associated with two-loci interactions of selected ADORA2A and DRD2 polymorphisms. The lowest dose of caffeine did not increase ratings of anxiety while the highest dose increased anxiety in the majority of subjects. These findings provide support for an association between an ADORA2A polymorphism and self-reported anxiety after a moderate dose of caffeine. It is likely that other ADORA2A and DRD2 polymorphisms also contribute to responses to caffeine.

Neuropsychopharmacology (2008) 33, 279I-2800; doi:I0.1038/npp.2008. 17; published online 27 February 2008
\end{abstract}

Keywords: caffeine; adenosine; dopamine; polymorphism; single nucleotide; anxiety

\section{INTRODUCTION}

Caffeine is the most widely used psychoactive substance in the world. In the United States, approximately $61 \%$ of the population consume caffeine daily (Dews et al, 1999). The mild psychomotor stimulant effects of caffeine, such as increases in alertness and arousal, are presumed to be the basis for its widespread use. However, at high doses, or in some individuals at moderate doses, caffeine produces anxiety and dysphoria. In particular, some people are sensitive to the anxiogenic effects of caffeine, perhaps because of polymorphisms in the genes that encode receptors where the drug acts. Thus, functional polymorphisms in genes relating to the central actions of caffeine may be related to anxiogenic responses to caffeine.

\footnotetext{
*Correspondence: Dr E Childs, The University of Chicago, 584I S Maryland Ave MC3077, Chicago, IL 60657, USA, Tel: + (773) 702 2718, Fax: + (773) 8347698 ,

E-mail: echilds@yoda.bsd.uchicago.edu

Received 14 September 2007; revised 18 December 2007; accepted 23 January 2008
}

The primary mechanism by which caffeine produces its central effects is by blocking adenosine receptors. At physiologically relevant concentrations, caffeine binds with high affinity to adenosine $A_{1}$ and $A_{2 A}$ receptors, antagonizing the effects of endogenous adenosine (Daly and Fredholm, 1998). Therefore, functional changes in these receptors caused by genetic variation could alter responses to caffeine. In fact, previously, our group (Alsene et al, 2003) reported an association between self-reported anxiety after caffeine and a single-nucleotide polymorphism (SNP) in the gene encoding the adenosine $\mathrm{A}_{2 \mathrm{~A}}$ receptor ( $A D O R$ $A 2 A)$. In this study, individuals with the $\mathrm{T} / \mathrm{T}$ genotype of the ADORA2A SNP rs5751876 (1976C/T) reported greater anxiety after $150 \mathrm{mg}$ caffeine compared to other genotypic groups. The same polymorphism has been linked to panic disorder (PD) (Deckert et al, 1998; Hamilton et al, 2004), suggesting that this variant confers a risk for anxiety states in general. Recently, we have also reported that individuals with the 1976T/T genotype also experience more anxiety after acute doses of the prototypic stimulant drug, D-amphetamine (Hohoff et al, 2005). As the ADORA2A $1976 \mathrm{C} / \mathrm{T}$ polymorphism is coding but synonymous (Deckert et al, 1996), it has been suggested that the nearly completely 
linked rs35320474 (2592T/-) polymorphism, $616 \mathrm{bp}$ downstream of the $1976 \mathrm{C} / \mathrm{T}$ polymorphism, may alter expression of the $\mathrm{A}_{2 \mathrm{~A}}$ receptor (Alsene et al, 2003). Whether this polymorphism is functional, or whether it is in linkage disequilibrium (LD) with other functional polymorphisms is yet to be determined.

The effects of caffeine may also be influenced by other neurotransmitter systems, including dopamine. Adenosine $A_{1}$ and $A_{2 A}$ receptors form functional heteromeric complexes with dopamine $D_{1}$ and $D_{2}$ receptors $\left(D_{R} D_{1 / 2}\right.$, Fuxe et al, 2005) and there is evidence that these receptors interact at multiple levels to control cell function. First, the receptors physically interact and binding of adenosine to $\mathrm{A}_{2 \mathrm{~A}}$ reduces affinity of $\mathrm{DRD}_{2}$ for dopamine (Torvinen et al, 2004). Second, there is reciprocal antagonism at the second messenger level reducing G-protein coupling and signaling. Activation of the $\mathrm{A}_{2 \mathrm{~A}}$ receptor stimulates adenylyl cyclase activity whereas activation of $\mathrm{DRD}_{2}$ inhibits adenylyl cyclase activity (Fuxe et al, 2003). Thus activation of $\mathrm{A}_{2 \mathrm{~A}}$ uncouples $\mathrm{DRD}_{2}$ from its $\mathrm{G}$ protein and reduces $\mathrm{DRD}_{2}$ signaling. Conversely, activation of $\mathrm{DRD}_{2}$ counteracts signaling via $\mathrm{A}_{2 \mathrm{~A}}$. Therefore, by antagonizing the actions of adenosine, caffeine acts indirectly to potentiate dopaminergic signaling. Indeed, dopaminergic manipulations affect the behavioral properties of caffeine. The motor stimulant effects of caffeine are reduced in $\mathrm{DRD}_{2}$ knockout mice (Chen et al, 2001; Zahniser et al, 2000) and $\mathrm{DRD}_{1}$ and $\mathrm{DRD}_{2}$ antagonists attenuate the discriminative stimulus effects of low caffeine doses (Powell et al, 1999). It is conceivable then that functional polymorphisms in the gene for the $\mathrm{DRD}_{2}$ receptor (DRD2) may also affect responses to caffeine.

In this study, we aimed to replicate and extend our previous finding that certain ADORA2A SNPs are associated with self-reported anxiety after $150 \mathrm{mg}$ caffeine. We tested the association in a separate group of subjects and also investigated these effects at other doses of caffeine $(0,50$, and $450 \mathrm{mg}$ ). Furthermore, we examined associations between self-reported anxiety after caffeine and additional genetic variations in $A D O R A 2 A$ and DRD2. As in the previous study, we assessed association in volunteers who consumed less than $300 \mathrm{mg}$ caffeine (approximately three cups) per week to minimize the influences of tolerance or dependence. We hypothesized that variation in ADORA2A rs5751876 (1976C/T) would predict self-reported anxiety after $150 \mathrm{mg}$ caffeine. We also predicted that genetic variation in DRD2 would affect anxiety after caffeine.

\section{MATERIALS AND METHODS}

\section{Subjects}

Male $(N=51)$ and female $(N=51)$ light, or non-caffeine consumers, aged 18-35 years, were recruited, without regard to race or ethnicity, from the University and surrounding community. Eligible participants attended a brief in-person psychiatric interview and physical examination including an electrocardiogram. Exclusion criteria included a current or prior diagnosis of Major Axis I DSM-IV disorder, any history of psychosis, daily smoking (Hart et al, 1976), less than a high-school education, lack of fluency in English, a body mass index outside of $19-26 \mathrm{~kg} / \mathrm{m}^{2}$, night shift work, high blood pressure, abnormal electrocardiogram, daily use of any medications, and in women, use of birth control pills, pregnancy, or breast feeding. Participants were queried about all dietary sources of caffeine upon which estimates of caffeine intake were based $(50 \mathrm{mg}$ per $12 \mathrm{oz}$ serving of caffeinated soft drinks, $60 \mathrm{mg}$ per $8 \mathrm{oz}$ serving of tea, $100 \mathrm{mg}$ per $8 \mathrm{oz}$ serving of coffee, and $10 \mathrm{mg}$ per bar of chocolate). Subjects kept a detailed diary of food and beverage consumption for 2 weeks prior to testing to confirm their initial self-reports. Participants' ethnicity was determined by self-report.

Before the study began, participants attended a short orientation session in which they read and signed the consent form, were familiarized with the experimental procedures, and completed personality and drug use questionnaires. The consent form stated that the study would investigate the effects of drugs upon mood and performance. For blinding purposes, volunteers were advised that they might receive one of several classes of drugs, including stimulants, tranquilizers, or inactive placebos.

\section{Design}

The study utilized a four-session, double-blind, placebocontrolled, within-subject design. Each subject received placebo, 50,150, or $450 \mathrm{mg}$ caffeine in random order during four test sessions conducted at least $72 \mathrm{~h}$ apart. Sessions were conducted from 0900 to $1300 \mathrm{~h}$.

\section{Procedure}

The University of Chicago Hospital's Institutional Review Committee for the use of human subjects approved the experimental protocol. Participants were tested individually in comfortably furnished rooms with a television/VCR, magazines, and a computer for administering questionnaires and tasks. They were allowed to watch television, movies, or read when no measures were being obtained, but they were not allowed to work or study.

Subjects refrained from eating from midnight on the night previous to sessions and were given a light snack on arrival in the laboratory at $0900 \mathrm{~h}$. Before ingesting the capsule, urine tests were conducted to detect recent drug use and breath samples collected to verify that they were alcohol free. No subjects tested positive. Subjects then completed pre-capsule subjective measures (Profile of Mood States (POMS), Visual Analog Scales (VAS); see below). At $0930 \mathrm{~h}$, subjects ingested a capsule containing placebo or caffeine $(50,150$, or $450 \mathrm{mg})$. Subjective measures were obtained again 30,60, and $90 \mathrm{~min}$ after capsule administration. Subjects also completed behavioral tasks and physiological data were obtained (heart rate, blood pressure) that are not included in this analysis.

\section{Subjective Anxiety}

The focus of this report is subjective anxiety, which was assessed using POMS (McNair et al, 1971) and VAS (Folstein and Luria, 1973).

The POMS is a 72 -item adjective checklist on which subjects report their current mood on a 5-point scale from 'not at all' (0) to 'extremely' (4). The adjectives comprising 
the anxiety scale included tense, shaky, on edge, panicky, relaxed, restless, uneasy, nervous, and anxious. The VAS consisted of a $100 \mathrm{~mm}$ horizontal line labeled with 'not at all anxious' at one end (score of 0 ) and 'extremely anxious' at the other (score of 100). Subjects were instructed to place a mark indicating how anxious they felt at that moment.

\section{Genotyping}

Table 1 shows the name, location, corresponding National Center for Biotechnology Information SNP identification numbers, and Celera Discovery System identification for the different ADORA2A and DRD2 SNPs. Primer-probe sequences and details of the PCR amplification and genotype-detection procedures are available from the corresponding author on request.

ADORA2A. Eight SNPs were chosen for genotyping the long form of ADORA2A (25 kb, UCSC Genome Browser, Human Mar.2006 Assembly) based on previous association studies (Alsene et al, 2003; Deckert et al, 1998) and the Hapmap database (rel no. 16, on NCBI B34 assembly, dbSNP b124, http://www.hapmap.org). Of these, six SNPs were within the gene (from $5^{\prime}$ to $3^{\prime}$ : rs5760405, rs2298383, rs3761422, rs2236624, rs5751876, and rs35320474) and two in the $\pm 10 \mathrm{~kb}$ flanking regions (rs5751862 and rs4822492; Table 1).

$D R D 2$ and ANKK1. Genotyping was performed by $5^{\prime}-$ exonuclease fluorescence assay (Shi et al, 1999). Seven SNP assays were used for DRD2 genotyping. From $5^{\prime}$ end to $3^{\prime}$ end, the SNPs were as follows: (1) rs1799978, (2) rs1799732,
(3) rs1079597, (4) rs1800498, (5) rs1110976, (6) rs6275, and (7) rs6279. The SNP formerly named DRD2 Taq1A, rs1800497, now identified as being in a novel kinase gene named ankyrin repeat and kinase domain containing 1 (ANKK1), was also genotyped. The probes and primers were designed by using Primer Express 2.0 (ABI Biosystem, CA).

\section{Drugs}

Caffeine was administered as caffeine citrate as it is more bioavailable than anhydrous caffeine. Caffeine citrate (Mallinckrodt Baker Inc., Paris, KY) was obtained from the University Hospital Pharmacy. Caffeine citrate doses are equivalent to approximately half the caffeine freebase dose. All data are expressed in $\mathrm{mg}$ of freebase caffeine. Doses of caffeine were administered in opaque gelatin capsules with dextrose as filler. Placebo capsules contained only dextrose.

\section{Data Analysis}

Subjects were assigned to one of the three genotypes at each locus. Hardy-Weinberg equilibrium was examined among the genotypes for each polymorphism (http://www. kursus. kvl.dk/shares/vetgen/_Popgen/genetik/applets/kitest.htm) and then LD analysis between alleles within the same gene (Genetix, V4.02). Genotype frequencies less than $n=10$ were dropped in subsequent analyses. Combining rare genotypes with other groups can diminish power in association studies due to molecular heterosis (Comings and MacMurray, 2000).

Differences in demographic characteristics between the genotypes at each locus were assessed by $\chi^{2}$ analysis

Table I ADORA2A, DRD2, and ANKKI SNPs and Corresponding ID in NCBI and Celera Database

\begin{tabular}{|c|c|c|c|c|c|}
\hline Gene and SNP & Location and nucleotide change & NCBI & Celera & Minor allele frequency & Reference \\
\hline \multicolumn{6}{|l|}{ ADORA2A } \\
\hline $5^{\prime}$-flank & 9.5 kb 5'-flank; A/G & rs575।862 & hCV2446647 & 0.50 & http://www.hapmap.org/ \\
\hline $263 C / T$ & Exon I; $263 \mathrm{C} / \mathrm{T}$ & rs5760405 & hCV29634682 & 0.144 & Alsene et al (2003) \\
\hline Intron la & Intron I; C/T & rs2298383 & hCVI6I89248 & 0.424 & http://www.hapmap.org/ \\
\hline Intron Ib & Intron I; C/T & rs376|422 & hCV2446666 & 0.367 & http://www.hapmap.org/ \\
\hline $2592 \mathrm{~T} /-$ & Exon 5; 2592 Ins/DelT & rs35320474 & & 0.484 & Alsene et al (2003) \\
\hline $3^{\prime}$-flank & 5.5 kb 3'-flank; C/G & rs4822492 & hCV26834592 & 0.40 & http://www.hapmap.org/ \\
\hline \multicolumn{6}{|l|}{ DRD2 } \\
\hline Intron 6 & Intron 6; Ins/DelG & rs I I 10976 & hCV7486676 & 0.156 & Finckh et al (1996) \\
\hline His3I3His & Exon 7; $939 \mathrm{C} / \mathrm{T}$ & rs6275 & hCV 2601173 & 0.3 & Peroutka et al (1998) \\
\hline Exon 8 & Exon 8; C/G & rs6279 & hCV 326647 & 0.302 & Finckh et al (1996) \\
\hline \multicolumn{6}{|l|}{ ANKKI } \\
\hline Glu7|3Lys & $7 / 3 \mathrm{C} / \mathrm{T}$ & rs|800497 & hCV748664I & 0.225 & Neville et al (2004) \\
\hline
\end{tabular}


(for categorical data) or independent samples $t$-test (for continuous data).

Subjective effects of caffeine for each subject were calculated as a peak change score for each separate session that is, $0,50,150$, and $450 \mathrm{mg}$ caffeine. The pre-capsule baseline was subtracted from the maximum response exhibited during $90 \mathrm{~min}$ after capsules were administered. The effect of order of dose presentation upon subjective responses was examined by two-factor (dose $\times$ order) analysis of variance (ANOVA) for repeated measures upon peak change scores. Originally, our group (Alsene et al, 2003) showed an association between self-reported anxiety and rs5751876 (1976C/T) genotype after $150 \mathrm{mg}$ caffeine in a sample of light infrequent caffeine consumers of all races. To compare the original findings with those of the current study, we first examined the association of ADORA2A rs5751876 (1976C/T) genotype with anxiety (VAS, POMS) after $150 \mathrm{mg}$ caffeine in the complete sample regardless of race. We performed a one-factor (genotype) ANOVA upon peak change scores. The issue of population stratification, that is, differences in allele frequency or phenotype between ethnic groups, is now widely acknowledged in genetic association studies and so all subsequent analyses were performed upon data obtained from European-American participants to avoid possible effects of population stratification. We examined associations between genotypes of individual ADORA2A SNPs with self-reported anxiety after $150 \mathrm{mg}$ caffeine using separate one-factor (genotype) ANOVA. Alpha was adjusted by Bonferroni correction for multiple testing at seven loci $(\alpha=0.007)$. Next, we performed individual two-factor (dose $\times$ genotype) ANOVA with repeated measures to assess interactions between individual ADORA2A SNPs and changes in anxiety after different doses of caffeine. Again, $\alpha$ was adjusted by Bonferroni correction for testing at seven loci within the same gene $(\alpha=0.007)$.

The same hierarchical procedure was used to explore relationships between genotypes of individual DRD2 polymorphisms and self-reported anxiety after caffeine in European-American participants. Throughout, $\alpha$ was adjusted by Bonferroni correction for multiple testing at eight loci $(\alpha=0.006)$.

The QTPHASE program of the UNPHASED suite (Dudbridge, 2003) was used to evaluate additive haplotypic effects of unphased genotype data upon reported anxiety after each caffeine dose. Peak change scores after placebo were subtracted from scores at each dose. Haplotype blocks were defined using Haploview (Barrett et al, 2005) and the solid spine of LD method. For ADORA2A, one block of high LD was detected including all markers (Figure 1), of which seven markers (rs5751862, rs5760405, rs2298383, rs3761422, rs2236624, rs5751876, rs4822492) were simultaneously tested using a single seven-locus window (the rs35320474 (2592T/-) polymorphism was dropped due to complete LD with rs5751876 (1976C/T); 2592T being completely linked to $1976 \mathrm{C}$ and $2592-$ to $1976 \mathrm{~T}$ and not $2592 \mathrm{C}$ to $1976 \mathrm{C}$ and $2592 \mathrm{~T}$ to $1976 \mathrm{C}$ as originally reported (Alsene et al, 2003)). For DRD2, LD identified three haplotype blocks (Figure 2); block $1=$ rs1799978 and rs1799732, block $2=\operatorname{rs} 1079597$ and rs1800498, block $3=$ rs1110976, rs6275, and rs6279, which were tested using two- and three-locus windows respectively. Uncertain haplotypes were estimated with an

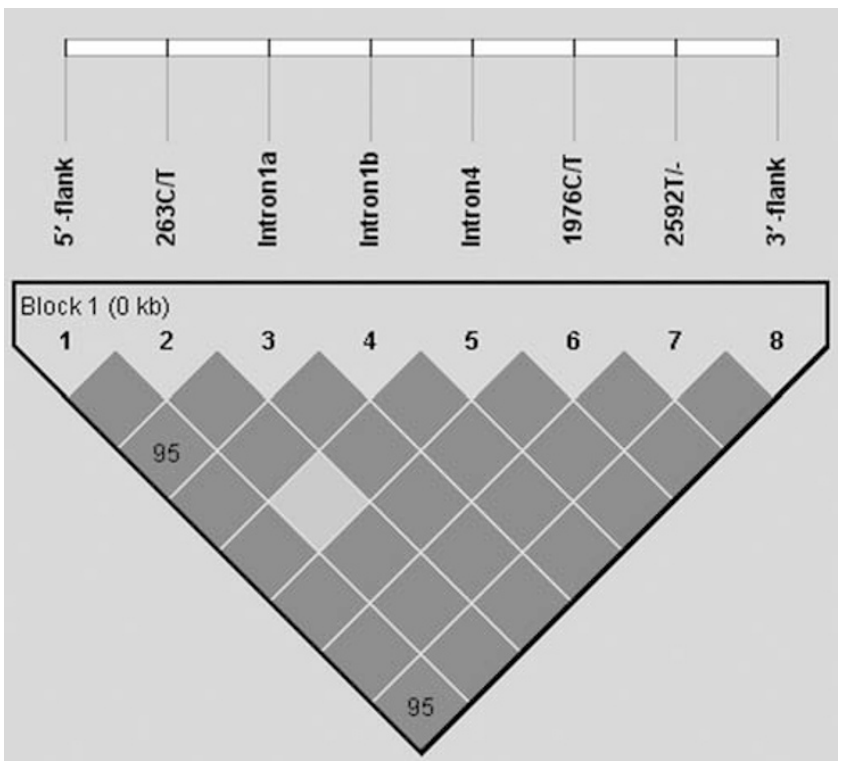

Figure I Linkage disequilibrium $\left(D^{\prime}\right)$ plot of ADORA2A in EuropeanAmerican participants. SNPs are shown by location as in Table I. Squares without numbers represent $D^{\prime}$ values of I.0; all numbers represent the $D^{\prime}$ value expressed as a percentile. Shaded squares represent pairs with LOD score for linkage disequilibrium of $\geqslant 2$ and white squares represent $\mathrm{LOD}<2$ and $D^{\prime}>$ I.0. Plots were generated using Genetix, V4.02.

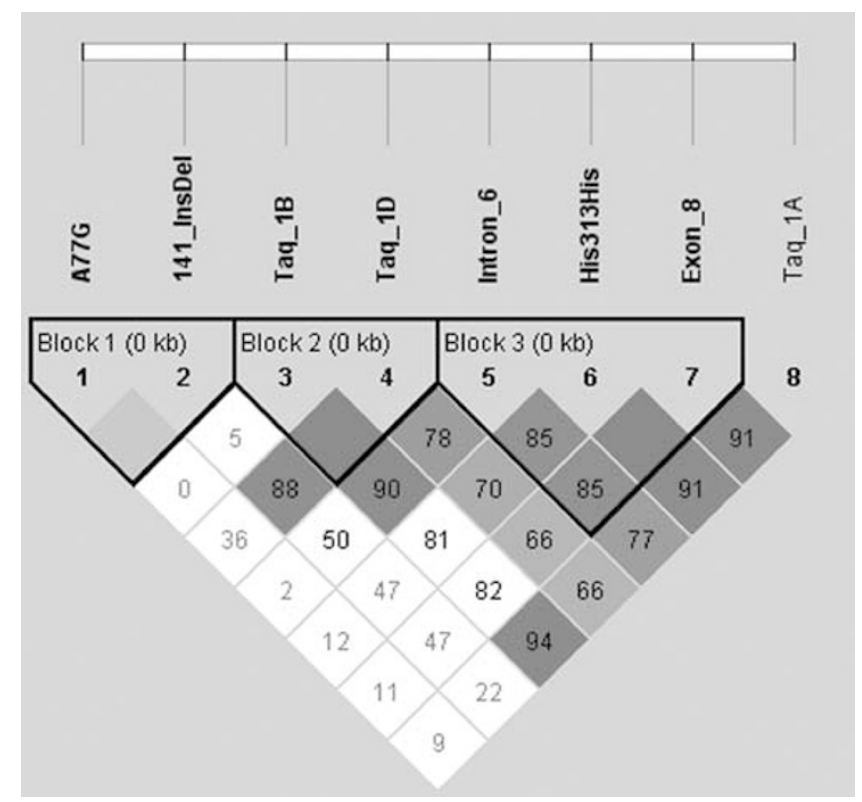

Figure 2 Linkage disequilibrium $\left(D^{\prime}\right)$ plot of $D R D 2$ in EuropeanAmerican participants. SNPs are shown by location as in Table I. Other details are as in Figure I.

expectation-maximization algorithm. Individual haplotypes were compared to all others grouped together. A permutation test was performed to correct significant haplotypes for multiple testing of haplotypes, loci, and phenotypes.

Restricted Partition Method (RPM, Culverhouse et al, 2004) was used to detect interactions between ADORA2A and $D R D 2$, looking at combinations of either SNPs or haplotypes. We applied the False Discovery Rate (FDR) 
method, as implemented in QVALUE (Storey, 2002), to correct for multiple testing. FDR is the expected proportion of false positives among the tests found to be significant. For a given set of analyses, QVALUE will utilize information from all the $P$-values and output a $Q$-value for each $P$-value. The $Q$-value of a test measures the minimum FDR that is incurred in calling that test significant. For example, for $Q$-value $\leqslant 0.1$, about $10 \%$ of the tests meeting this threshold will be false positives. Storey (2002) has shown that the $Q$-value is conservative and will exceed the true FDR. Associations with combinations of 1 and 2 variants (SNPs or haplotypes) were analyzed, using one variant from each gene in the two-locus interaction. We followed the conventions of Millstein et al (2006) and applied the FDR separately to the one- and two-locus analyses.

\section{RESULTS}

\section{Demographic Data and Effects of Caffeine}

Demographic characteristics of participants are shown in Table 2. Most volunteers were European-American in their early twenties. The average consumption of caffeine in milligrams per week was $116 \pm 10.5$, which is equivalent to just over one cup of coffee per week.

Caffeine had its expected effects on subjective state and vital signs, when all subjects were considered together.

Table 2 Participant Characteristics, Current and Lifetime Drug Use

\begin{tabular}{|c|c|c|}
\hline $\begin{array}{l}\text { Demographic } \\
\text { characteristic }\end{array}$ & $\begin{array}{l}\text { All population } \\
\text { groups }\end{array}$ & $\begin{array}{l}\text { European- } \\
\text { American }\end{array}$ \\
\hline N & 102 & 62 \\
\hline Age & $21.6 \pm 0.3$ & $20.7 \pm 0.3$ \\
\hline Sex (male/female) & $5|/ 5|$ & $32 / 30$ \\
\hline Weight (lbs) & $149.6 \pm 2.3$ & $149.0 \pm 2.7$ \\
\hline \multicolumn{3}{|l|}{ Race } \\
\hline \% European-American & 60.8 & 100 \\
\hline$\%$ African-American & 18.6 & \\
\hline$\%$ Asian-American & 17.7 & \\
\hline$\%$ Other & 2.9 & \\
\hline \multicolumn{3}{|l|}{ Current drug use } \\
\hline Alcoholic drinks per week & $3.6 \pm 0.4$ & $4.4 \pm 0.6$ \\
\hline Caffeine cups per week & $1.2 \pm 0.1$ & $1.2 \pm 0.1$ \\
\hline Cigarettes per month & $3.5 \pm 2.8$ & $5.3 \pm 4.5$ \\
\hline Marijuana per month & $0.9 \pm 0.3$ & $0.6 \pm 0.06$ \\
\hline \multicolumn{3}{|l|}{ Lifetime drugs use (\% ever used) } \\
\hline Stimulants & 6.0 & 6.5 \\
\hline Sedatives & 5.0 & 8.2 \\
\hline Hallucinogens & 10.8 & 12.9 \\
\hline Opiates & 27.5 & 30.6 \\
\hline Marijuana & 55 & 56.5 \\
\hline Inhalants & 5.0 & 4.8 \\
\hline
\end{tabular}

Data represent mean \pm SEM.
These effects have been reported in detail elsewhere (Childs and de Wit, 2006). Only the highest dose (450 mg) significantly increased ratings of anxiety (VAS; Figure 3 ).

\section{Hardy-Weinberg Equilibrium and Genotype Distributions}

There were no significant deviations from Hardy-Weinberg expectations for ADORA2A, DRD2, or ANKK1 polymorphisms.

The genotype distribution for each of the polymorphisms is shown in Table 3. Genetic data could not be analyzed for some subjects due to problems in extracting DNA. Rare genotypes $(n<10)$ were dropped from analyses to avoid loss of power due to effects of molecular heterosis (Comings and MacMurray, 2000) and therefore sample sizes were smaller for some analyses. Rare genotypes not included in the analyses were ADORA2A rs5760405 263C/T T/T, rs2236624 Intron $4 \mathrm{~T} / \mathrm{T}, \quad D R D 2 \quad \mathrm{rs} 1799978$ A77G G/G, rs1799732 141InsDel -/-, rs1079597 Taq1B A/A, rs1110976 Intron 6 -l-, rs6275 His313His T/T, rs6279 Exon 8 C/C, rs1800497 Glu713Lys T/T.

Most of the association analyses were performed upon data from European-American participants only; however, here we report differences in genotype frequency between races for completeness. There was a significant effect of race upon genotype for the DRD2 SNPs rs1799732 141InsDel $\left(\chi^{2}=17.4, \mathrm{df}=2, P<0.001\right)$, rs1800498 Taq1D $\left(\chi^{2}=43.8\right.$, $\mathrm{df}=4, P<0.001)$, and rs1110976 Intron $6\left(\chi^{2}=11.8, \mathrm{df}=2\right.$, $P=0.003)$. For rs1799732 (141InsDel), most EuropeanAmerican and Asian-American participants were C/C, while African-American participants were C/-. For rs 1800498 Taq1D, most European-American participants were G/A, while most African-American and Asian-American participants were G/G. For rs1110976 Intron 6, most EuropeanAmerican and African-American participants were G/G, while most Asian-American participants were G/-. There was no significant effect of race or the other demographic variables upon genotype distribution of any ADORA2A SNPs.

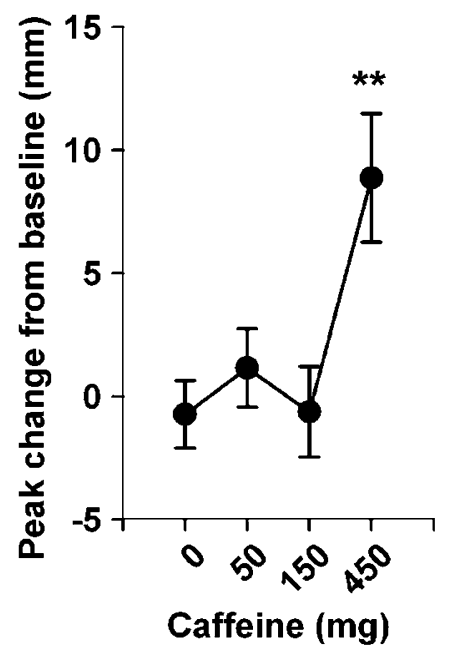

Figure 3 Change in self-reported anxiety (VAS) after different doses of caffeine. Data represent mean \pm SEM peak change from pre-capsule baseline in participants from all population groups. Asterisks denote significant difference from placebo (post hoc pairwise comparisons; *** $P<0.0$ I). 


\section{Association between ADORA2A Polymorphisms and Anxiety}

There was a significant effect of rs5751876 1976C/T genotype upon VAS anxiety after $150 \mathrm{mg}$ caffeine $(\mathrm{F}(2,98)=3.5$, $P<0.05)$ in the entire data set. Individuals with the $\mathrm{T} / \mathrm{T}$ genotype reported the highest anxiety $(4.6 \pm 1.9)$ and $\mathrm{C} / \mathrm{C}$ individuals reported the least anxiety after $150 \mathrm{mg}$ caffeine $(-7.5 \pm 3.7)$. When data for European-American participants were considered, this effect was no longer significant $(\mathrm{F}(2,59)=2.1, P=0.1$; Figure 4$)$.

Table 3 Allele and Genotype Distribution of ADORA2A and DRD2 Polymorphisms for European-American (EA) Participants

\begin{tabular}{|c|c|c|c|c|c|}
\hline \multirow[b]{2}{*}{ Polymorphism } & \multicolumn{2}{|c|}{ Allele } & \multicolumn{3}{|c|}{ Genotype } \\
\hline & $\mathbf{I}$ & 2 & $1 / 1$ & $1 / 2$ & $2 / 2$ \\
\hline \multicolumn{6}{|l|}{$A_{2 A}$ receptor gene } \\
\hline rs575। 862 & $56(A)$ & $68(\mathrm{G})$ & $13(\mathrm{AA})$ & $30(A G)$ & $19(G G)$ \\
\hline rs5760405 & $97(C)$ & $27(T)$ & $38(C C)$ & $21(\mathrm{CT})$ & $3(T)$ \\
\hline rs2298383 & $55(C)$ & $69(T)$ & $14(C C)$ & $27(\mathrm{CT})$ & $21(T T)$ \\
\hline rs376|422 & $75(C)$ & $49(\mathrm{~T})$ & $24(\mathrm{CC})$ & $27(\mathrm{CT})$ & II (TT) \\
\hline rs2236624 & $96(C)$ & $28(T)$ & $38(\mathrm{CC})$ & $20(\mathrm{CT})$ & $4(\Pi)$ \\
\hline$r s 5751876^{a}$ & $73(C)$ & $51(\mathrm{~T})$ & $23(C C)$ & $27(\mathrm{CT})$ & $12(T \mathrm{~T})$ \\
\hline rs35320474 & $73(\mathrm{~T})$ & $51(-)$ & $23(\mathrm{TT})$ & $27(T-)$ & $12(--)$ \\
\hline rs4822492 & $69(\mathrm{G})$ & $55(C)$ & $21(\mathrm{GG})$ & 27 (GC) & $14(C C)$ \\
\hline \multicolumn{6}{|c|}{$D R D_{2}$ receptor gene } \\
\hline rs|799978 & $98(A)$ & $10(G)$ & $45(\mathrm{AA})$ & $8(A G)$ & I (GG) \\
\hline rs|799732 & $98(C)$ & $12(-)$ & 43 (CC) & $12(\mathrm{C}-)$ & $-(--)$ \\
\hline rs 1079597 & $9(A)$ & $95(\mathrm{G})$ & $-(\mathrm{AA})$ & $9(A G)$ & 43 (GG) \\
\hline rs| 800498 & $44(\mathrm{G})$ & $64(A)$ & $6(\mathrm{GG})$ & $32(\mathrm{GA})$ & $16(\mathrm{AA})$ \\
\hline rs III0976 & $95(\mathrm{G})$ & $15(-)$ & $42(\mathrm{GG})$ & I| (G-) & $2(--)$ \\
\hline rs6275 & $7 \mid(C)$ & $39(\mathrm{~T})$ & $21(C C)$ & $29(\mathrm{CT})$ & $5(\Pi)$ \\
\hline rs6279 & $40(C)$ & $70(\mathrm{G})$ & $6(C C)$ & 28 (CG) & 21 (GG) \\
\hline rs|800497 & $90(C)$ & $18(\mathrm{~T})$ & 38 (CC) & I4 (CT) & $2(\pi)$ \\
\hline
\end{tabular}

aalues for individuals from all population groups are alleles $101(C), 103(T)$; genotypes 29(CC), 43(CT), 30 (TT).
There were significant effects of genotype for other SNPs upon VAS anxiety after $150 \mathrm{mg}$ caffeine (Figure 4). For rs2298383 Intron 1a, that is nearly in complete LD with rs4822492 3'-flank, individuals with the C/C genotype at each locus reported significantly higher anxiety than those with the $\mathrm{T} / \mathrm{T}$ genotype at the rs2298383 Intron 1a locus and G/G at the rs4822492 $3^{\prime}$-flank locus $(F(2,59)=5.5, P=0.007)$.

Association analyses between changes in anxiety after different doses of caffeine and single ADORA2A SNPs revealed several trends. For rs2298383 Intron 1a/rs4822492 3 '-flank, individuals with the $\mathrm{C} / \mathrm{C}$ genotype at each locus tended to report more anxiety than other genotypes at moderate $(150 \mathrm{mg})$ and high $(450 \mathrm{mg})$ doses of caffeine (POMS anxiety, $\mathrm{F}(6,174)=2.7, P=0.016)$. There was also a trend for a main effect of genotype for rs5751862 $5^{\prime}$-flank (POMS anxiety, $\mathrm{F}(2,58)=4.4, P=0.017)$ and an interaction between dose and genotype for rs3761422 Intron $1 \mathrm{~b}$ (VAS anxiety, $\mathrm{F}(6,177)=2.5, P=0.023$ ).

Haplotypic association analyses identified three haplotypes of ADORA2A polymorphisms that significantly affected ratings of VAS anxiety after $50 \mathrm{mg}$ caffeine (individual $P$ s $<0.05$, global $P<0.01$ ). However, the significant association did not remain after a permutation test that corrected for multiple testing (permutation $P=0.09$ ). There was no significant association between the haplotypes and ratings of anxiety after other doses of caffeine.

\section{Association between DRD2 and ANKK1 Polymorphisms and Anxiety}

There was a significant effect of rs1110976 Intron 6 genotype upon ratings of VAS anxiety after $150 \mathrm{mg}$ caffeine $(P=0.005$; Figure 5$)$. Individuals with the G/- genotype reported higher anxiety than G/G individuals. There were no other significant associations between individual genotypes or haplotypes and anxiety after $150 \mathrm{mg}$ caffeine or interaction with effects at other doses.

\section{Interactive Effects of ADORA2A, DRD2, and ANKK1 Polymorphisms upon Anxiety}

The analysis of two-loci interactions showed significant main effects for selected ADORA2A and DRD2 SNP
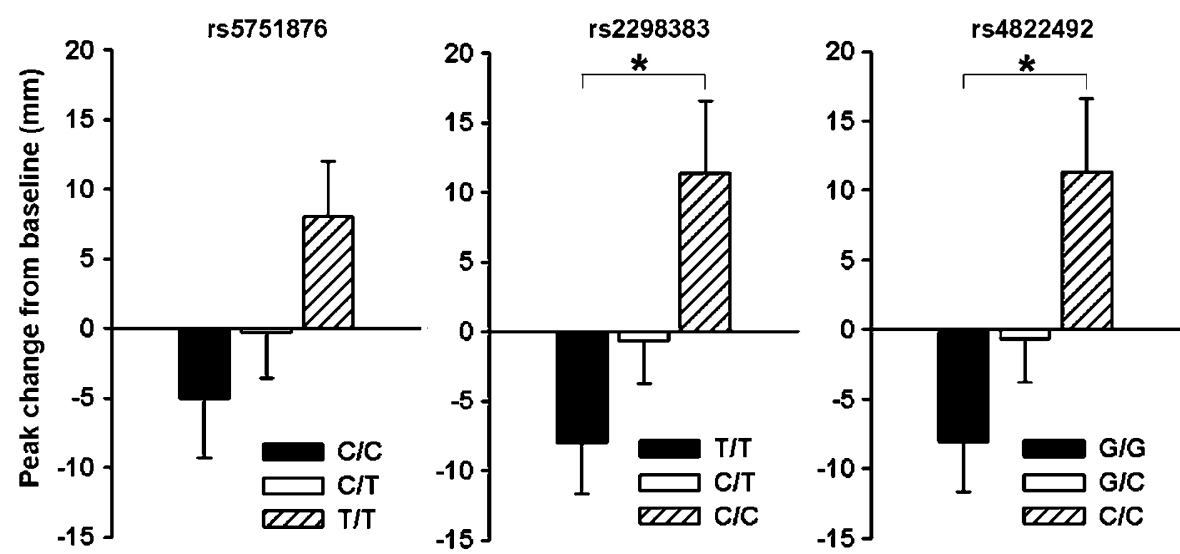

Figure 4 Changes in anxiety (VAS) for genotypic groups of ADORA2A rs575I876 1976C/T, rs2298383 Intron Ia, and rs4822492 3'-flank after I 50 mg caffeine in European-American participants. Bars represent mean \pm SEM peak change from pre-capsule baseline. Asterisks denote significant difference between groups (post hoc multiple comparisons; $* P<0.007$ ). 
polymorphisms upon ratings of VAS anxiety that remained significant after correction for multiple testing. These interactions produced higher ratings of anxiety after $150 \mathrm{mg}$ caffeine. There was a significant interaction between ADORA2A rs5751862 5'-flank and DRD2 rs1079597 Taq1B. The ADORA2A rs2298383 Intron 1a/rs4822492 3'-flank polymorphism interacted significantly with several of the DRD2 polymorphisms: rs1799978 A77G; rs1079597 Taq1B; rs1110976 Intron 6; and rs1800497 Glu713Lys. The specific genotypes of separate polymorphisms for these interactions and the corresponding $R^{2}$ and $Q$-values are given in Table 4 .

There were no significant interactions between haplotypes of ADORA2A and DRD2 SNPs upon ratings of anxiety.

\section{DISCUSSION}

This study aimed to examine associations between the anxiety-inducing effect of caffeine and genotypes of $A D O R A 2 A$ and DRD2 polymorphisms. In the group as a whole, caffeine $(0,50,150$, or $450 \mathrm{mg})$ produced its expected effects (Childs and de Wit, 2006), and only the highest dose increased self-reported anxiety. We replicated and extended

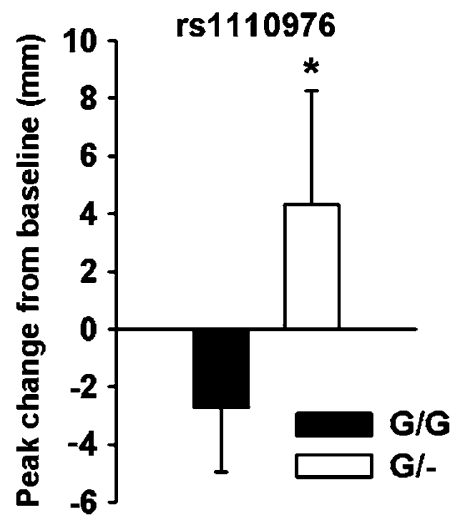

Figure 5 Changes in anxiety (VAS) after $150 \mathrm{mg}$ caffeine in EuropeanAmerican participants for genotypic groups at DRD2 rs I I 0976 Intron 6. Bars represent mean \pm SEM peak change from pre-capsule baseline. The asterisk denotes a significant difference between the genotypes $(P<0.006)$. our previous finding of an association between the ADORA2A 1976C/T SNP and anxiety after $150 \mathrm{mg}$ of caffeine. We observed several significant associations between this phenotype and other ADORA2A and DRD2 polymorphisms, and also combinations of ADORA2A and DRD2 SNPs.

Ratings of anxiety after $150 \mathrm{mg}$ caffeine differed significantly between genotypes at the ADORA2A rs5751876 $1976 \mathrm{C} / \mathrm{T}$ receptor gene polymorphism locus. When data from all population groups were considered, individuals with the $\mathrm{C} / \mathrm{C}$ genotype reported the smallest increase in anxiety and those with the T/T genotype reported the greatest increase in anxiety. This confirms our previous finding (Alsene et al, 2003) and provides further evidence that this locus is linked to enhanced sensitivity to anxiogenic effects after caffeine at doses equivalent to 1-2 cups of coffee. More recently, the effects of population stratification have been widely recognized and statistical methods have been designed to account for these effects in analyses of data from heterogeneous populations (Enoch et al, 2006). However, in the absence of information on participants' ancestry, data obtained from a homogeneous population must be considered to avoid the possible confounds of population stratification. Thus, we performed all additional analyses upon data obtained from EuropeanAmerican participants. In this smaller data set, the association between rs5751876 1976C/T genotype and anxiety response was no longer significant, most likely due to the loss of power with the reduced sample size. However, the same genotypic effect was present and individuals with the T/T genotype reported more anxiety after caffeine than those with the $\mathrm{C} / \mathrm{C}$ genotype. Interestingly, the T allele of rs5751876 1976C/T has previously been associated with $\mathrm{PD}$, a condition characterized by attacks of fear and anxiety. Deckert et al (1998) found that PD patients had a higher prevalence of the $1976 \mathrm{~T}$ allele compared to controls. Hamilton et al (2004) also report an association between this locus and susceptibility to PD. Therefore, our data suggest that responses to $150 \mathrm{mg}$ caffeine might be examined further to investigate $\mathrm{A}_{2 \mathrm{~A}}$ receptor-mediated mechanisms of anxiety.

Table 4 Interactive Effects of Single ADORA2A, DRD2, and ANKKI Polymorphisms Upon Anxiety after $150 \mathrm{mg}$ Caffeine in EuropeanAmerican Participants

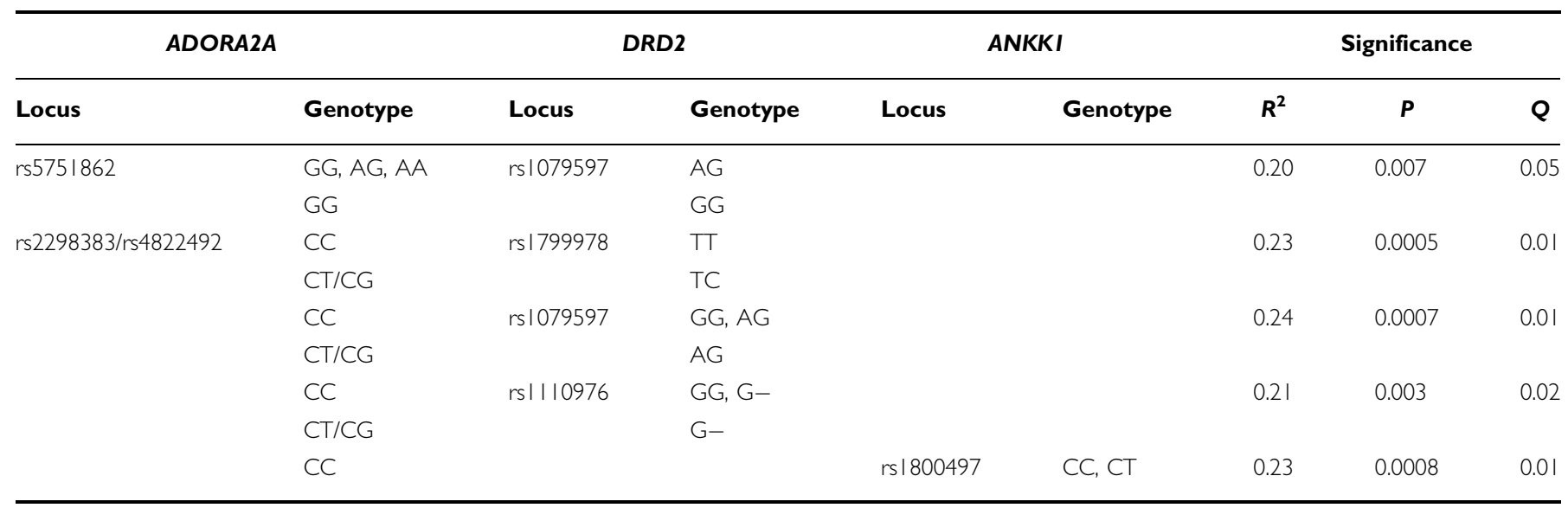

Genotype combinations significantly increase anxiety. 
There are two likely explanations that may account for the similar finding that ADORA2A rs5751876 1976C/T genotype is associated with anxiety response to $150 \mathrm{mg}$ caffeine between our two studies; either population stratification is similar between the two study samples or we have identified an association that is valid across population groups. The only way to distinguish between the two accounts is to examine association within each population group, which unfortunately is not possible here, given the small sample size. Therefore, in future, we aim to investigate the association of this SNP with caffeine-induced anxiety in other population groups.

We found that ratings of anxiety after $150 \mathrm{mg}$ caffeine differed between genotypes of the ADORA2A rs2298383 Intron $1 \mathrm{a} / \mathrm{rs} 48224923^{\prime}$-flank polymorphisms and DRD2 rs1110976 Intron 6 polymorphisms. These ADORA2A polymorphisms have not been investigated previously and their functional consequence is unknown. However, Yu et al (2004) suppose the rs2298383 Intron 1a polymorphism to be located in one of the potential promoter regions upstream of several newly identified ADORA2A exon 1 variants (at position 21521648 of chromosome 22, UCSC, Nov. 2002 freeze). In silico analysis using the online tool PupaSuite (Conde et al, 2006) has revealed the location of the rs2298383 Intron 1a polymorphism within a triplex-forming oligonucleotide target. This position is potentially functionally relevant since these sequences are described to regulate gene expression (Goni et al, 2004). Further, the minor allele of the DRD2 rs1110976 Intron 6 polymorphism, which was associated with low anxiety in this study, has previously been linked to reduced striatal density of $\mathrm{DRD}_{2}$ receptors (Ritchie and Noble, 2003). Adenosine $\mathrm{A}_{2 \mathrm{~A}}$ and dopamine $\mathrm{DRD}_{2}$ receptors interact together in a reciprocally antagonistic manner (Fuxe et al, 2003; Torvinen et al, 2004). Caffeine, by antagonizing the action of adenosine at $\mathrm{A}_{2 \mathrm{~A}}$ receptors, acts indirectly to potentiate dopaminergic transmission. Therefore, it is plausible that the behavioral effects of caffeine may be attenuated in individuals with lower dopamine $\mathrm{DRD}_{2}$ receptor density.

Interaction analyses discovered ADORA2A and DRD2 polymorphisms that together significantly increased anxiety after $150 \mathrm{mg}$ caffeine. Several of these single SNPs had already been significantly associated with caffeine-induced anxiety (ie ADORA2A rs2298383 Intron 1a/rs4822492 $3^{\prime}$ flank, $D R D 2$ rs1110976 Intron 6), although the analyses revealed other ADORA2A and DRD2 SNPs and also the ANKK1 SNP, which previously were not significantly associated with anxiety response. The explanation for this is that genotypic effects of SNP combinations accounted for more of the variability in anxiogenic responses to caffeine than each individual SNP. The DRD2 polymorphisms (rs1079597 Taq1B, rs1110976 Intron 6) and also the ANKK1 SNP rs1800497 Glu713Lys are known to functionally alter dopamine receptor density in the striatum (Arinami et al, 1997; Jonsson et al, 1999; Ritchie and Noble, 2003). For DRD2 rs1079597 Taq1B and rs1110976 Intron 6, the genotypes associated with significantly greater response to caffeine included alleles of the SNP that were previously associated with higher receptor density in the striatum.

The gene-gene interactions between ADORA2A and DRD2 did not persist when SNP haplotypes were considered. There are differences between the analyses that were used for testing association of haplotypes within a gene (QTPHASE) and between genes (RPM), which might account for the different results. QTPHASE is able to incorporate information from ambiguous haplotypes and analyze all the possible haplotypes for a set of genotypes, weighting by the probability of each haplotype. For RPM, only the most likely haplotype for each set of genotypes could be used. Therefore, lower frequency haplotypes would provide less information for the RPM analysis than for the QTPHASE analysis, potentially leading to different results.

In general, ratings of anxiety did not differ between ADORA2A genotypes after the 50 or $450 \mathrm{mg}$ doses of caffeine, which may account for the lack of significant interaction between genotype and caffeine dose. However, there were some trends to significant interactions between genotype and dose for rs2298383 Intron 1a/rs4822492 3'flank and rs3761422 Intron $1 \mathrm{~b}$ that may reach significance in a larger sample. Overall, these data suggest that the $150 \mathrm{mg}$ dose (equivalent to approximately $12 \mathrm{oz}$ of nongourmet coffee) may be close to the threshold for producing anxiogenic effects and as such might be the optimal dose to detect genotypic effects. Usually, low doses of caffeine do not produce anxiety in healthy volunteers and high doses of caffeine might produce a strong effect in most subjects, which likely overcomes subtle genotypic effects.

One limitation of this study is the relatively small sample size, particularly for analyses performed in the EuropeanAmerican subsample $(N=62)$. Our sample sizes of 101 (all population groups) and 62 (European-American participants) are small when compared to those traditionally used in case-control association studies for categorical phenotypes, but are in line with those of other pharmacogenetic studies with dimensional phenotypes (Mattay et al, 2003). Although all of the individual gene findings in this study were significant after correction for multiple testing, we must still apply caution to their interpretation until they are replicated in a larger sample size.

A unique feature of this study was that it was conducted in a sample of light caffeine consumers, who were not dependent on the drug. By selecting these subjects, we minimized variability related to caffeine tolerance, or, if the subjects had been required to abstain from caffeine, caffeine withdrawal. However, some have argued that a sample of light infrequent caffeine consumers is not representative of the general population and that these individuals may be self-selecting due to heightened sensitivity to adverse effects of caffeine including anxiety (James and Rogers, 2005). In fact, both the positive and negative subjective, and also physiological effects of caffeine in the present study were similar to those previously reported in other populations (Evans and Griffiths, 1991; Griffiths et al, 1990; Hughes, 1996) and there was little evidence that these samples were more sensitive to the aversive effects of caffeine (Childs and de Wit, 2006). A recent study also suggests that as high as $39 \%$ of the general population consumes amounts of caffeine comparable to those reported by our subjects (Dews et al, 1999). In addition, the frequencies of the $A D O R A 2 A$ and DRD2 variants in the present study are similar to those reported by the National Center for Biotechnology Information (NCBI) public SNP database (dbSNP, http://www.ncbi.nlm.nih.gov/projects/SNP/). Therefore, we have no reason to suspect that our sample is enriched 
with individuals who experience caffeine-induced anxiety or express the associated $A D O R A 2 A$ and $D R D 2$ variants. We also excluded daily smokers from our sample due to the variability this might introduce into caffeine responses (Hart et al, 1976). We do not feel that this criterion renders the sample nonrepresentative since epidemiological studies show strong relationships between caffeine consumption and smoking (Swanson et al, 1994); thus one might expect that light caffeine consumers involved in this experiment are more likely non-smokers. However, recently Cornelis et al (2007) reported that individuals with the rs5751876 1976T/T genotype were more likely to be lighter caffeine consumers than those individuals carrying a $\mathrm{C}$ allele. In addition, the relationship was stronger in smokers than in non-smokers. Therefore, future studies should also investigate associations in high-caffeine users and smokers to probe the relevance of our findings to these groups.

In conclusion, the present study replicated and extended the findings of our previous study (Alsene et al, 2003). The T/T genotype of the rs5751876 $1976 \mathrm{C} / \mathrm{T}$ polymorphism in ADORA2A was significantly associated with anxiogenic responses to $150 \mathrm{mg}$ caffeine. We also found significant associations between other ADORA2A and DRD2 receptor gene polymorphisms and anxiety after caffeine. Finally, we report combinations of ADORA2A and DRD2 polymorphisms that account for more variance in caffeine-induced anxiety than the individual SNPs alone. Throughout, alleles of functional DRD2 polymorphisms that have previously been associated with reduced receptor density were associated with diminished responses to caffeine. However, at this stage, these additional findings must be considered exploratory and should be replicated and confirmed in future studies.

\section{ACKNOWLEDGEMENTS}

This research was supported by NIDA (DA02812) and the General Clinical Research Center (USPHS MO1RR000555). We thank Michelle Dassinger, Liz Young, Lisa Vicini, Maliha Darugar, and Kathrin Schwarte for their technical assistance.

\section{DISCLOSURE}

All authors reported no biomedical financial interests or potential conflicts of interest.

\section{REFERENCES}

Alsene K, Deckert J, Sand P, de Wit H (2003). Association between $\mathrm{A}_{2 \mathrm{a}}$ receptor gene polymorphisms and caffeine-induced anxiety. Neuropsychopharmacology 28: 1694-1702.

Arinami T, Gao M, Hamaguchi H, Toru M (1997). A functional polymorphism in the promoter region of the dopamine D2 receptor gene is associated with schizophrenia. Hum Mol Genet 6: $577-582$.

Barrett JC, Fry B, Maller J, Daly MJ (2005). Haploview: analysis and visualization of LD and haplotype maps. Bioinformatics 21: 263-265.

Chen JF, Moratalla R, Impagnatiello F, Grandy DK, Cuellar B, Rubinstein $M$ et al (2001). The role of the $D_{2}$ dopamine receptor $\left(D_{2} R\right)$ in $A_{2 A}$ adenosine receptor $\left(A_{2 A} R\right)$-mediated behavioral and cellular responses as revealed by $\mathrm{A}_{2 \mathrm{~A}}$ and $\mathrm{D}_{2}$ receptor knockout mice. Proc Natl Acad Sci USA 98: 1970-1975.

Childs E, de Wit H (2006). Subjective, behavioral, and physiological effects of acute caffeine in light, nondependent caffeine users. Psychopharmacology (Berl) 185: 514-523.

Comings DE, MacMurray JP (2000). Molecular heterosis: a review. Mol Genet Metab 71: 19-31.

Conde L, Vaquerizas JM, Dopazo H, Arbiza L, Reumers J, Rousseau F et al (2006). PupaSuite: finding functional single nucleotide polymorphisms for large-scale genotyping purposes. Nucleic Acids Res 34: W621-W625.

Cornelis MC, El-Sohemy A, Campos H (2007). Genetic polymorphism of the adenosine $\mathrm{A}_{2 \mathrm{~A}}$ receptor is associated with habitual caffeine consumption. Am J Clin Nutr 86: 240-244.

Culverhouse R, Klein T, Shannon W (2004). Detecting epistatic interactions contributing to quantitative traits. Genet Epidemiol 27: $141-152$.

Daly JW, Fredholm BB (1998). Caffeine-an atypical drug of dependence. Drug Alcohol Depend 51: 199-206.

Deckert J, Nothen MM, Franke P, Delmo C, Fritze J, Knapp M et al (1998). Systematic mutation screening and association study of the $\mathrm{A} 1$ and $\mathrm{A} 2 \mathrm{a}$ adenosine receptor genes in panic disorder suggest a contribution of the A2a gene to the development of disease. Mol Psychiatry 3: 81-85.

Deckert J, Nothen MM, Rietschel M, Wildenauer D, Bondy B, Ertl MA et al (1996). Human adenosine A2a receptor (A2aAR) gene: systematic mutation screening in patients with schizophrenia. J Neural Transm 103: 1447-1455.

Dews PB, Curtis GL, Hanford KJ, O’Brien CP (1999). The frequency of caffeine withdrawal in a population-based survey and in a controlled, blinded pilot experiment. J Clin Pharmacol 39: 1221-1232.

Dudbridge F (2003). Pedigree disequilibrium tests for multilocus haplotypes. Genet Epidemiol 25: 115-121.

Enoch MA, Shen PH, Xu K, Hodgkinson C, Goldman D (2006). Using ancestry-informative markers to define populations and detect population stratification. J Psychopharmacol 20: 19-26.

Evans SM, Griffiths RR (1991). Dose-related caffeine discrimination in normal volunteers: individual differences in subjective effects and self-reported cues. Behav Pharmacol 2: 345-356.

Finckh U, Giraldo-Velasquez M, Pelz J, Otto G, Sander T, Schmidt LG et al (1996). Dopamine D2 receptor gene (DRD2) haplotypes in Caucasians. Gene 179: 251-255.

Folstein MF, Luria R (1973). Reliability, validity, and clinical application of the visual analogue mood scale. Psychol Med 3: 479-486.

Fuxe K, Agnati LF, Jacobsen K, Hillion J, Canals M, Torvinen M et al (2003). Receptor heteromerization in adenosine A2A receptor signaling: relevance for striatal function and Parkinson's disease. Neurology 61: S19-S23.

Fuxe K, Ferre S, Canals M, Torvinen M, Terasmaa A, Marcellino D et al (2005). Adenosine A2A and dopamine D2 heteromeric receptor complexes and their function. J Mol Neurosci 26: 209-220.

Gelernter J, Kranzler H, Cubells JF, Ichinose H, Nagatsu T (1998). DRD2 allele frequencies and linkage disequilibria, including the -141CIns/Del promoter polymorphism, in European-American, African-American, and Japanese subjects. Genomics 51: 21-26.

Goni JR, de la Cruz X, Orozco M (2004). Triplex-forming oligonucleotide target sequences in the human genome. Nucleic Acids Res 32: 354-360.

Griffiths RR, Evans SM, Heishman SJ, Preston KL, Sannerud CA, Wolf B et al (1990). Low-dose caffeine discrimination in humans. J Pharmacol Exp Ther 252: 970-978.

Hamilton SP, Slager SL, De Leon AB, Heiman GA, Klein DF, Hodge $\mathrm{SE}$ et al (2004). Evidence for genetic linkage between a polymorphism in the adenosine $2 \mathrm{~A}$ receptor and panic disorder. Neuropsychopharmacology 29: 558-565. 
Hart P, Farrell GC, Cooksley WG, Powell LW (1976). Enhanced drug metabolism in cigarette smokers. BMJ 2: 147-149.

Hohoff C, McDonald JM, Baune BT, Cook EH, Deckert J, de Wit H (2005). Interindividual variation in anxiety response to amphetamine: possible role for adenosine $\mathrm{A}_{2 \mathrm{~A}}$ receptor gene variants. Am J Med Genet B Neuropsychiatr Genet 139: 42-44.

Hughes R (1996). Drugs which induce anxiety: caffeine. $N Z$ J Psychol 25: 36-42.

James JE, Rogers PJ (2005). Effects of caffeine on performance and mood: withdrawal reversal is the most plausible explanation. Psychopharmacology (Berl) 182: 1-8.

Jonsson EG, Nothen MM, Grunhage F, Farde L, Nakashima Y, Propping $\mathrm{P}$ et al (1999). Polymorphisms in the dopamine D2 receptor gene and their relationships to striatal dopamine receptor density of healthy volunteers. Mol Psychiatry 4: 290-296.

Kidd KK, Morar B, Castiglione CM, Zhao H, Pakstis AJ, Speed WC et al (1998). A global survey of haplotype frequencies and linkage disequilibrium at the DRD2 locus. Hum Genet 103: 211-227.

Mattay VS, Goldberg TE, Fera F, Hariri AR, Tessitore A, Egan MF et al (2003). Catechol o-methyltransferase val158-met genotype and individual variation in the brain response to amphetamine. Proc Natl Acad Sci USA 100: 6186-6191.

McNair D, Lorr M, Droppleman L (1971). Profile of Mood States. Educational and Industrial Testing Service: San Diego.

Millstein J, Conti DV, Gilliland FD, Gauderman WJ (2006). A testing framework for identifying susceptibility genes in the presence of epistasis. Am J Hum Genet 78: 15-27.

Neville MJ, Johnstone EC, Walton RT (2004). Identification and characterization of ANKK1: a novel kinase gene closely linked to DRD2 on chromosome band 11q23.1. Hum Mutat 23: 540-545.
Parsian A, Cloninger CR, Zhang ZH (2000). Functional variant in the DRD2 receptor promoter region and subtypes of alcoholism. Am J Med Genet 96: 407-411.

Peroutka SJ, Price SC, Wilhoit TL, Jones KW (1998). Comorbid migraine with aura, anxiety, and depression is associated with dopamine D2 receptor (DRD2) NcoI alleles. Mol Med 4: $14-21$.

Powell KR, Koppelman LF, Holtzman SG (1999). Differential involvement of dopamine in mediating the discriminative stimulus effects of low and high doses of caffeine in rats. Behav Pharmacol 10: 707-716.

Ritchie T, Noble EP (2003). Association of seven polymorphisms of the D2 dopamine receptor gene with brain receptor-binding characteristics. Neurochem Res 28: 73-82.

Shi MM, Myrand SP, Bleavins MR, de la Iglesia FA (1999). High throughput genotyping for the detection of a single nucleotide polymorphism in $\mathrm{NAD}(\mathrm{P}) \mathrm{H}$ quinone oxidoreductase (DT diaphorase) using TaqMan probes. Mol Pathol 52: 295-299.

Storey J (2002). A direct approach to false discovery rates. $J R$ Statist Soc B 64: 479-498.

Swanson JA, Lee JW, Hopp JW (1994). Caffeine and nicotine: a review of their joint use and possible interactive effects in tobacco withdrawal. Addict Behav 19: 229-256.

Torvinen M, Kozell LB, Neve KA, Agnati LF, Fuxe K (2004). Biochemical identification of the dopamine D2 receptor domains interacting with the adenosine A2A receptor. J Mol Neurosci 24: 173-180.

Yu L, Frith MC, Suzuki Y, Peterfreund RA, Gearan T, Sugano S et al (2004). Characterization of genomic organization of the adenosine a2a receptor gene by molecular and bioinformatics analyses. Brain Res 1000: 156-173.

Zahniser NR, Simosky JK, Mayfield RD, Negri CA, Hanania T, Larson GA et al (2000). Functional uncoupling of adenosine $\mathrm{A}(2 \mathrm{~A})$ receptors and reduced response to caffeine in mice lacking dopamine D2 receptors. J Neurosci 20: 5949-5957. 